\title{
O Direito Civil Tende a Desaparecer?
}

\author{
Antônio Junqueira de Azevedo \\ Professor Livre-Docente de Direito Civil na Facul- \\ dade de Direito da Universidade de São Paulo.
}

\section{Introdução.}

A pergunta, que serve de título ao presente artigo, é formulada com o profundo temor de que uma aperfeiçoadíssima construção do espírito humano venha a se transformar em algo apenas histórico; ela encobre o medo de que toda a beleza e toda a força de um determinado sistema jurídico, tal e qual já ocorreu com o direito romano, venha a perder sua significação para a maior parte das pessoas, afastando-se, assim, do presente e da vida. Irá o direito civil, indagamos qual nova Cassandra, caminhar solemente para a História, para aí permanecer? $\mathrm{Ou}$, em hipótese um pouco melhor, tornarse-á refúgio de especialistas? Perderá ele aquele seu caráter, que nos ensinaram, de direito comum em relação aos outros ramos do direito? Deixará ele também de ser o direito do simples cidadão? P'erderá ele finalmente, o lugar, como diz RENE DAvID (Les grands systèmes de droit contemporains, Dalloz, Paris, 1966, 2.a ed., p. 20) de "sede por excelência da nossa ciência do direito"?

Essas indagações assaltam o pobre espírito de um professor de direito civil que procura não perder contacto com a realidade dos dias que correm. RENE SAVATIER (Les metamorphoses economiques et sociales du droit civil d'aujourd'hui, Dalloz, Paris, 1964, 3 ème edition) depois de arrolar as transformações por que passam as concepções "burguesas" sobre a fortuna adquirida e a família legítima, expressa aproximada- 
mente o mesmo temor, dizendo: "A profundidade dêsses problemas deixa ao professor de direito civil, se ele vive, simultâneamente, a vida de um homem de seu tempo, a impressão de um certo obsoletismo do ensino tradicional, do qual ele está encarregado, na mesma linha do ensino que ele próprio recebeu".

Realmente, na medida em que se sai dos conceitos mais abstratos, das grandes classificações, ou dos primeiros princípios, e se passa aos institutos em espécie, isto é, na medida em que, no campo do direito civil, se mergulha mais próximo do concreto, sente-se a existência de uma certa desatualização. Essa desatualização se manifesta de duas formas. Em primeiro lugar, porque há alguns institutos, que se tornaram "antigos", em virtude exatamente da menor importância que, como diz o citado professor francês, a "fortuna adquirida" (em geral herdada) tem na economia atual. Isso é particularmente claro no direito das sucessões, explicando-se, perfeitamente, o olhar desinteressado dos alunos, quando se expõem, por exemplo, os problemas do legado de coisa alheia, as normas sobre fideicomisso, sobre direito de acrecer entre herdeiros e legatários, sobre codicilo e os testamentos especiais. Tudo, afinal, tão distante do que acontece para as pessoas em geral! $\mathrm{O}$ fenômeno, pelas mesmas causas, é também sensível no direito das coisas, em que as fortunas constituídas de imóveis perderam grande parte daquela aura de superioridade sobre as de bens móveis; aí, a enfiteuse e a anticrese já estão, até mesmo, se tornando conhecidas entre estudantes, de tão pouco comuns que são (supra-sumo do paradoxo!) ; masi há também o direito real de uso e as rendas constituídas sobre imóveis. A final, convenhamos, tudo bastante estranho para uma pessoa comum.

A segunda forma pela qual se manifesta a desatualização é menos saliente que a anterior, mas, talvez, seja mais importante. Trata-se do aparente excesso de minúcia, em certas questões, nas quais, ao que se deduz, a vida moderna não quer perder tanto tempo; assim, as "sutilezas" da distinção 
entre prescrição e decadência (que acaba, na prática, sendo a seguinte: na decadência o prazo não se suspende nem se interrompe e, na prescrição, sim); as diferenças entre obrigações solidárias e indivisíveis; também certas formas de extinção das obrigações (imputação do pagamento, novação, reinissão de dívidas, etc.), ou, no próprio direito de família, que vái se tornando a cidadela da resistência aos ataques contra o direito civil, a ordem dos obrigados ao dever de alimentos (que raríssimamente é exigido além do primeiro grau na linha direta), ou o regime dotal. Toda essa desatualização do direito civil e de seu estudo é para fazer pensar!

No fundo, é toda uma concepção de vida, a liberal-igualitária, de que o direito civil era um dos melhores exemplos, que (infelizmente!) está a fazer água. O primeiro passo da "evoluçãoo" é, evidentemente, a transformação do direito civil, de direito comum e de direito do simples cidadão, em direito especializado, isto é, direito para certas situações ou, até, para certas pessoas. Esse é o momento que estamos vivendo. Depois, a continuar a tendência, ele perderá também seu caráter de direito-base da ciência do direito e, finalmente, quando tudo ficar submergido sob novas roupagens, aquilo, que apaixonadamente aprendemos sob o nome de "direito civil", será sòmente histórico. As poucas pessoas, que, então, com ele entrarem em contacto, tal e qual turistas na Sainte-Chapelle, perceberão a beleza, a delicadeza e a fôrça de construção, mas, em geral, pouco ou nada perceberão do significado da obra, da fé, que a fêz.

\section{As tendências.}

A contínua decadência das concepções liberais e igualitárias, em proveito das autoritárias e hierarquizantes, dá demonstrações evidentes de sua existência em todo o vasto campo da Cultura, incluindio-se, aí, o direito. No campo do direito público, a sempre difícil conciliação entre a liberdade e a igualdade parece que está levando, em todo o mundo, ao de- 
saparecimento de ambas. O princípio republicano da legalidade sucumbe diante do princípio monárquico da autoridade. No campo do direito privado, o fenômeno, como incoercível mancha de óleo, está penetrando profundamente; nele, o direito civil está a se transformar substancialmente e, a continuar assim, acabará por desaparecer.

Podemos verificar a existência dessa tendência anti-liberal e anti-igualitária, no direito civil, através das seguintes manifestações: 1) - Quanto às normas jurídicas, caminhamos, de normas clássicas, que são regras de conduta, claras e precisas, que as partes conhecem e espontâneamente aplicam, a normas decadentes, que são simples indicações para um juiz, colocado super partes, decidir no caso concreto; e de leis supletivas, a um número cada vez maior de leis cogentes (é a chamada "publicização dio direito civil") ; 2) - Quanto aos sujeitos de direito, a pessoa jurídica subordina a atividade das pessoas físicas; estas, reduzidas a condição de "órgãos" daquela, se supra e infraordenam dentro dela, é a hierarquia da instituição; 3) -- Quanto aos objetos de direito, bens tangíveis perdem importância diante de bens intangíveis, como "cargos de direção" numa empresa, ou como "cartas patentes", "exclusividades", "cotas de fornecimento", etc, que são concedidas ao particular, pela administração pública ou por empresas monopolísticas; 4) Quanto aos fatos jurídicos, o negócio jurídico, uma das grandes criações da civilização liberal-igualitária, no campo do direito civil, antes, por definição, ato livre, quanto a gênese, e realizado no interesse do agente, quanto à função, sofre um verdadeiro assalto nesses dois aspectos. Depois do contrato de adesão e do contrato-tipo, já se fala em contrato forçado; e os efeitos dos contratos, que eram obrigatórios por terem sido escolhidos pelo agente, deixam de ser, no "interêsse social"; 5) - Finalmente, quanto às situações jurídicas, é esta outra maravilhosa criação jurídica, o direito subjetivo, que está sendo suplantado pela situação, dita de "poder", que supõe submissão e hierarquia. 
Se corrermos os olhos por tôdas essas mudanças, notamos logo que o princípio republicano, de liberdade e igualdade entre os homens, com a submissão reduzida, tanto quanto possível, apenas à lei, vai sendo suplantado, no próprio direito civil, pelo princípio monárquico, que admite amplamente a submissão de um homem a outro; ou, sob outro ângulo, é a justiça comutativa, que, no dizer de RADBRUCH, é a justiça nas relações entre elementos no mesmo pé de igualdade, que vai sendo suplantada, no nosso próprio campo, pela justiça distributiva, que é justiça nas relações de subordinação entre elementos que se acham em pé de desigualdade.

\section{As normas jurídicas.}

Começando pelo exame dessas tendências nas normas jurídicas, lembramos, inicialmente, a passagem de leis, que, por sua redação, são fàcilmente auto-aplicáveis, para leis, cuja formulação abre largo campo de ação ao juiz; é o que se verifica, por exemplo, com as novas redações dadas pela Lei n. ${ }^{\circ} 4.121$, de 1962 (Estatuto da Mulher Casada), aos arts. 326 e 380, do Código Civil, ambos no próprio baluarte civilístico, o direito de família; essas duas alterações são expressivas, não tanto por transformarem uma situação preexistente, mas sim, por, num caso (\$ único, do atual art. 380), autorizarem expressamente o juiz a resolver, super partes, um conflito entre marido e mulher, e, no outro (art. 326), a decidir, discricionariamente, no desquite judicial, em que os dois cônjuges são considerados culpados, com quem devem ficar os filhos (antigamente, embora com ressalvas, até os seis anos de idade, os filhos e as filhas ficavam sob a guarda da mãe e, depois dessa idade, os filhos passavam para a guarda do pai, continuando as meninas com a mãe. Hoje, nenhuma dessas distinções existe, o juiz decide no interesse dos menores).

De início, feitas inconscientemente, as novas fórmulas de redação, em que se deixa largo arbítrio ao juiz, tornando-se antes indicações de como o magistrado deve decidir, são, ho- 
je, adotadas conscientemente, pelos juristas sintonizados com a época presente. A fim de não nos alongarmos em exemplos, lembramos, a propósito, as palavras, sempre esclarecedoras, ainda quando delas se divirja, do prof. MIGUEL REALE, na Exposição de Motivos, do Anteprojeto de Código Civil: "O que se tem em vista é, em suma, uma estrutura normativa concreta, isto é, destituída de qualquer apego a meros valores formais abstratos. Esse objetivo de concretude impõe soluções que deixam larga margem de ação ao juiz e à doutrina, com freqüente apelo a valores como os de boa-fé, eqüidade, probi dade, finalidade social do direito, equivalência das prestações, etc., o que talvez não seja do agrado dos partidários de uma concepção mecânica ou naturalística do Direito, o qual, todavia, é incompatível com leis rígidas de tipo físico-matemático"

Ainda, sobre as normas jurídicas, são cada vez mais numerosas as leis ditas de ordem pública, assunto, a que dedicaremos mais algumas palavras ao tratarmos do negócio jurídico.

\section{As Pessoas e os Bens.}

O ser humano que, hoje, na nossa economia moderna, age autônomamente para o seu ganha-pão, está na mesma situação do célebre cavaleiro que, depois de viver "en un lugar de la Mancha, de cujo nombre no quiero acordarme", um dia, deixou sua casa el passou a vagar pelas terras de Espanha. Tem ambos o mesmo anacronismo. O comum, atualmente, como é notório, é que as pessoas físicas submetam sua atividade a uma pessoa jurídica. O que nem sempre se vê, e muito menos se fala, é que haja subordinação das pessoas físicas à pessoa jurídica; às vêzes, se diz que a atividade de todos é coordenada pela pessoa jurídica para se atingir um fim comum; essa linguagem, porém, leva a engano. A pessoa jurídica, na verdade, submete a si a atividade das pessoas físicas; o que há é uma subordinação da pessoa natural, ao titular dessa atividade, que é a pessoa jurídica; e, se não ficarmos na análise meramente formal da situação, e formos ainda adiante e examinarmos microscopicamente o que se passa dentro da insti- 
tuição, vemos que, interna corporis, as próprias pessoas físicas se super e sub-ordinam umas às outras. Essa tendência hierarquizante, piramidal, monárquica, é tão forte que mesmo os mais graduados, dentro de uma empresa, hoje desejam se colocar na condição de empregados da pessoa jurídica, a fim de auferirem "benefícios sociais" (segurança trabalhista, vantagens da previdência social, vantagens fiscais, etc.)

Tal situação repercute também no campo dos bens; a direção da empresa torna-se, pelas oportunidades de altos salários e gratificações, um bem muito maior que qualquer imóvel bem localizado. Já não importa muito ter ações de uma sociedade anônima; o interessante é dirigí-la, porque isto representa simultâneamente um poder sobre inúmeras outras pessoas e uma fonte de riqueza diante de todas.

A revolução no campo dos bens, se manifesta também através das "cartas-patentes", das "quotas de fornecimento", das "concessões", etc. Basta pensarmos no valor que representa, no patrimônio da pessoa coletiva, a quota de uma usina de açúcar, a carta-patente de uma financeira, ou de uma corretora, a concessão pelo poder público de determinada linha para uma empresa de transporte, ou até mesmo, a "representação", que uma grande empresa particular dê a outrem para atuar em seu nome, em certo território. São valores intangíveis somente concebíveis, em termos de hierarquia e subordinação.

\section{O Negócio Jurídico}

O negócio jurídico ("ato jurídico", no nosso Código Civil), em cuja construção científica tanto se empenhou a doutrina civilística em uma de suas fases áureas, sofreu e vem sofrendo grandes mudanças quanto a sua gênese e quanto a sua função. Especialmente o contrato, já não é, na maioria das vêzes, aquele ato livre, entre pessoas iguais, cujos efeitos são deliberadamente procurados pelas partes, no seu próprio interesse.

O contrato deixou de ser um produto da liberdade de querer das partes ("autonomia da vontade") e quanto a seus 
efeitos, a lei, ora lhe tira alguns, dos que estavam na intenção das partes, ora acrescenta outros, que não estavam. Há algum tempo, vem os civilistas apontando essas alterações do direito contratual. Silvio Rodrigues (Direito Civil, v. III, Edição Saraiva, 1972, 4. ${ }^{\mathrm{a}}$ ed., p. 19) diz: "Tanto o princípio da autonomia de vontade como o da obrigatoriedade das convenções perderam uma parte de seu prestígio, em face de anseios e preocupação novas, nem sempre atendidos no apogeu do regime capitalista. . A verificação de tais circunstâncias conduziu o legislador a intenvir no contrato, para remediar os efeitos da desigualdade existente. Fê-lo usando do próprio mecanismo, acima explicado, ou seja, criando, para limitar a autonomia da vontade, novas normas de ordem pública, contra as quais esbarra a liberdade de estipular. Assim, entre nós, vimas aparecer a Lei da Usura, as leis do inquilinato, a Lei de Luvas, etc"

Agora, entretanto, continuamos nós, a evolução foi ainda mais longe; as mais recentes normas de ordem pública já não se explicam pelo louvável anseio do legislador em prol da igualdade das partes, e' sim, declaram visar diretamente o próprio interêsse social. É o que, em geral, acontece com os tabelamentos de preços, as autorizações administrativas necessárias para grande número de negócios, as fiscalizações, etc. Pensemos em instituições estatais como o Banco Central, a sunAB, o CIP, O INCRA, o Instituto do Açúcar e do Alcool e o Instituto Brasileiro do Café, que todas limitam, decisivamente, a atividade do particular, em obediência a "razões de Estado", relacionadas com a política econômica do país. Sintomáticamente, a própria legislação sobre locações - assunto tradicionalmente de direito privado - teve regra importantíssima colocada em lei de caráter econômico (a chamada Lei de Estímulos à Construção Civil, Lei n.o 4.864, de 1965) e a ação de despejo foi, depois, considerada matéria de "segurança nacional" (cfr. os "consideranda" do Decreto-Lei n. " 4, de 1966)!

$\mathrm{Na}$ verdade, seria preciso distinguir, nesse ponto, as antigas normas de ordem pública, que eram, ou são, predominan- 
temente protetivas, visando, em matéria contratual, a manter equilibrada a economia interna do acordo de vontade, e as atuais normas de ordem pública, que são eminentemente diretivas, e procuram "enquadrar" os contratos, para que eles se façam no mesmo sentido atribuído à economia do país (cfr. Jean Huser, Objectivismie et subjectivisme dans l'acte juridique, L.G.D.J., Paris, 1971, p. 140) Bem examinadas umas e outras, (sem radicalizar as conseqüências da distinção, que se baseia no caráter predominante), somente as últimas trazem uma real diminuição do direito civil, as anteriores se constituem, antes, em vigorosas afirmações de liberdade e igualdade. Por isso mesmo, embora em alguns casos se chegue até a extinção completa de qualquer liberdade de contratar (hoje, por exemplo, todos os estabelecimentos comerciais abertos ao público são obrigados a vender sem discriminações contra quem quiser comprar) não são essas hipóteses, ou outras, em que a inspiração é também protetiva (normas sobre contrato de trabalho, anulação por lesão, anulação por ato realizado em estado de perigo, etc.), as em que se pode apontar uma decadência do direito civil. Decadência haverá quando se tratar de normas de ordem pública eminentemente econômicas; por exemplo, a fixação das principais condições contratuais em leis e decretos especiais, como, em geral, os preços de produtos tabelados, que não são poucos, nem os menos importantes; ou, então, a proibição de que certos contratos sejam realizados pelas partes sem a autorização dd poder público, com'o vendas, incorporações, fusões, e transformações, de estabelecimentos bancários, instituições financeiras e corretoras. Nessas hipóteses não será no republicano direito civil, e sim, infelizmente, no monárquico direitơ público (direito econômico, administrativo, fiscal, penal, etc.) que os "contratantes" encontrarão as normas que mais lhe interessam. Aliás, incidentalmente, observamos que, em geral, essas normas não serão uma "lei", no sentido romano ("lex est quod populus jubet atque constituit", Garo, Institutiones, I,3), mas sim, uma "portaria", que um funcionário editou com base numa "resolução", que, 
por sua vez, outro funcionário mais graduado promulgou, com base num "regulamento", que, por sua vez, outro funcionário ainda mais graduado, publicou com base num decreto etc. tudo em obediência ao princípio da hierarquia, próprio do direito público.

\section{O Direito Subjetivo.}

Por fim, vejamos o direito subjetivo, entendido como a prerrogativa pré-estabelecida pela lei, cujo titular, em princípio, dela poderá ou não usar, inclusive, e especialmente, fazendo-a objeto de negócio jurídico .O direito subjetivo tem, aparentemente, escapado da evolução anti-civilistica; aliás, a bem dizer, cle início, quando se reflete sobre o assunto, tem-se a impressão de que houve um alargamento do instituto. Desde o princípio do século que, cada vez mais, alguns bens vem sendo considerados "direitos", sem que antes o fossem; por exemplo: o direito ao nome, a direito à própria imagem, o direito à vida, à integridade física, à honra, à intimidade. Entretanto ainda que não sigamos integralmente a PAUL Roubier (Droits subjectifs et situation juridiques, Dalloz, Paris, 1963, p. 364), para quem nenhum desses "direitos" é realmente direito subjetivo, concordamos com o citado autor, quando diz que há um abuso da palavra "direito" (obra citada, p. 47) De fato, sob a palavra "direito", tem-se colocado, não só verdadeiros direitos subjetivos, tais como uma propriedade, um crédito, uma "universitas juris", mas também simples interesses juridicamente protegidos; por outras palavras, o abuso da palavra "direito" leva a se atribuir ao nome "direito subjetivo" tôda a esfera do. lícito. Daí que, quando se trata, por exemplo, de uma norma, que nos obriga a respeitar a vida alheia, ao invés de se explicar a realidade jurídica tal qual é, vendo-se que há, aí, somente um dever geral de respeito mútuo, peca-se por excesso de subjetivismo e procura-se ver, com sede em cada pessoa, um direito à vida. Dessa forma, multiplicam-se, ao infinito, esses "direitos", e também naturalmente os deveres a eles ligados, já que, a cada direito à vida, corresponderão correlatos 
deveres de todas as outras pessoas (infinito vezes infinito). Essa maneira de ver não só complica qualquer explicação sobre o fenômeno jurídico, como, principalmente, torna impossível distinguir o que é verdadeiro direito subjetivo do que é, apenas, um interesse protegido por uma norma objetiva. $\mathrm{O}$ verdadeiro direito subjetivo não é toda e qualquer vantagem que a lei assegura a alguém, e sim, somente aquela perrogativa pré-estabelecida, ou seja, aquela prerrogativa que se pode como que manipular, manusear, isto é, aquela prerrogativa pré-estabelecida que pode ser objeto de negócio jurídico. $€$ isto que ocorre com uma propriedade, ou um crédito, que podem ser transferidos, cedidos, renunciados, etc; e não é o que acontece, por exemplo, com o "direito" à vida, com o "direito" ao trabalho, com o "direito" à intimidade, com o "direito" à legalidade dos atos do poder público, com o "direito" de ir e vir e assim por diante.

O excessivo alargamento do "direito subjetivo", é, assim, no fundo, apenas uma perda de sentido do próprio conceito; bem examinada a situação, ao invés de força, de vitalidade, como ocorreria se, cada vez, um maior número de bens se tornassem direitos subjetivos, o que há é uma imprecisão de linguagem, em virtude da qual vamos chamando "direitos" o que direito não é. Em conseqüência, os verdadeiros direitos acabam por se descaracterizar, no meio de outras situações jurídicas diversas deles.

Se fosse somente isso, porém, a situação não seria tão ruim; o problema é ainda mais grave. Com efeito, hoje, os próprios verdadeiros direitos subjetivos estão desaparecendo, por causa de uma má compreensão de sua função; mais e mais, se passa a ver, erroneamente, em cada direito subjetivo, individualmente considerado, uma função social. Antigamente, em linha de princípio, um direito subjetivo determinado era atribuído a alguém no interesse desse alguém e ficava entregue à sua vontade usá-lo ou não. Entendia-se que através dele, o seu titular procuraria ter as condições de vida que de- 
sejasse. $\mathrm{O}$ interesse social de dar a cada pessoa boas condições de vida usava do instituto jurídico do direito subjetivo, por entender que, através dele, cada um, por conta própria, utilizaria a prerrogativa pré-estabelecida na lei, segundo suas próprias conveniências. (Ah, belos tempos!)

A função social do direito subjetivo era, assim, dele, somente quando genericamente considerado; ela justamente consistia em que cada direito subjetivo, individualmente considerado, estava em função do próprio titular. Hoje, está se perdendo esse sentido do direito subjetivo. A função social do direito subjetivo já não é dele genericamente considerado, e sim, estamos quase a ver a "função social" de cada determinado direito subjetivo. Já não é a propriedade, que tem função social, e sim, uma propriedade específica; ora, se for assim, e levando-se o raciocínio até o fim (ponto a que historicamente ainda não chegamos, mas para o qual tendemos), o proprietário, que deve usar a sua propriedade de acordo com a função social, quer dizer, que deve usar sua propriedade no interesse social, já não tem um direito, tem é um dever. Ele é alguém que cumpre uma função (é um "funcionário"), e, não já, o "proprietário", o "dono" (Eu sou o dono!"), com toda a conotação que essas palavras tem. Se há normas, que lhe dão pouca ou nenhuma liberdade de ação, se, por exemplo, elas determinam quanto se deverá pagar pelos produtos de suas terras, a quem ele osi deverá vender, ou até, quais os produtos que deverá plantar sob pena de vir a ser desapropriado ou confiscado e, ainda, além de tudo, o proprietário deve ter presente que sua atividade deve ser exercida, não no seu interesse, mas sim, no interesse social, a situação, òbviamente, já não é a de quem tem direito de propriedade. No fundo, êsse proprietário é simples "administrador", que administra o que, por força de inércia, continuamos a dizer "sua" propriedade.

Tudo aquilo que nós poderíamos ver como as suas vantagens, na verdade, nessa hipótese, ser-lhe-iam atribuídas (ou toleradas?) em atenção a certos fins, que o ultrapassam. Ora, 
se as suas vantagens estão na exata dependência de fins que o ultrapassam, a situação jurídica já não é a de "direito subjetivo"; é uma situação comuníssima dentro do direito público e a que podemos chamar de "poder institucional" (quem tem o poder, o tem por causa, e na medida da função, que exerce) ; o titular do "poder institucional" está submetido a controle de uma autoridade superior (que, por sua vez, está submetida a outra mais alta e, assim, indefinidamente) Logo, mais uma vez, saímos integralmente do nosso republicano direito civil, para mergulharmos, profundamente, no âmago do monárquico direito público.

\section{Conclusão .}

$\mathrm{E}$, assim, prezado leitor que me acompanhou até aqui, somos obrigados a terminar com o mesmo pessimismo com que começamos. Certamente, durante algum tempo, ainda, o direito civil, hoje já sem sua característica de direito comum e cle pessoas comuns, continuará, graças a sua aperfeiçoada técnica, a ser o direito-base da ciência do direito; ele fornecerá, ainda por algum tempo, aos outros ramos do direito, modelos para as elaborações científicas, enriquecendo-os (é a partilha em vida do espólio civilístico) Depois, - e agora com base na evolução orgânica das culturas, quase passamos a exercer a difícil arte da profecia - se vier mesmo o fim das civilização liberal-igualitária, cuja decadência estamos assistindo, o direito civil não escapará. Dele, poderá permanecer um resíduo, como o que uma época deixa para a que vem após si, mas estaremos inteiramente sob a batuta autoritária do direito público. Como este, no nosso sistema jurídico romano-germânico (cfr. RENÊ DAvid, Les Grands Systémes de Droit Contemporains, DALloz, p. 84) é muito menos direito que o direito privado, estaremos em época pouco jurídica. Infelizmente, a se confirmar a hipótese, esta será a situação, até que novos tempos, com novas exigências de liberdade e igualdade, venham provocar um renascimento republicano e a re-invenção do direito civil. Por ora, ainda que procurando, fiéis até o fim, 
aperfeiçoar nossa ciência, e mesmo sem aceitar tudo como necessidade histórica, não podemos deixar de concluir com SPENGLER, que "devemos incluir nos nossos cálculos, os duros e frios fatos de uma vida vivida numa fase tardia. Essa nossa época não foi escolhida por nós. Não podemos alterar o fato de termos nascido como homens do incipiente inverno da civilização amadurecida". 